\title{
Effect of Sintering on In Vivo Biological Performance of Chemically Deproteinized Bovine Hydroxyapatite
}

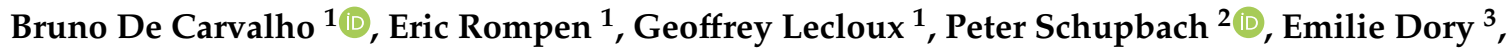 \\ Jean-François Art $^{3}$ and France Lambert ${ }^{1, *}$ \\ 1 Department of Periodontology and Oral Surgery, University of Liège, 4000 Liège, Belgium; \\ bruno.decarvalho@chuliege.be (B.D.C.); eric.rompen@wishbone-biotech.com (E.R.); \\ geoffrey.lecloux@chuliege.be (G.L.) \\ 2 Adjunct Professor, Augusta University, Augusta, GA 1120, USA; pmschupbach@mac.com \\ 3 Department of Biomaterials, WishBone SA, 4000, Liège, Belgium; emilie.dory@wishbone-biotech.com (E.D.); \\ jean-francois.art@wishbone-biotech.com (J.-F.A.) \\ * Correspondence: france.lambert@chuliege.be
}

Received: 27 September 2019; Accepted: 25 November 2019; Published: 28 November 2019

check for updates

\begin{abstract}
The influence of the manufacturing process on physicochemical properties and biological performance of xenogenic biomaterials has been extensively studied, but its quantification on bone-to-material contact remains poorly investigated. The aim of this study was to investigate the effect of different heat treatments of an experimental chemically-deproteinized bovine hydroxyapatite in vivo in terms of new bone formation and osteoconductivity. Protein-free hydroxyapatite from bovine origin was produced under sub-critical conditions and then either sintered at $820^{\circ} \mathrm{C}$ or $1200^{\circ} \mathrm{C}$. Structural and morphological properties were assessed by scanning electron microscopy (SEM), measurement of surface area and X-ray diffractometry (XRD). The materials were then implanted in standardized alveolar bone defects in minipigs and histomorphometric evaluations were performed using non-decalcified sections. Marked topographical differences were observed by SEM analysis. As the sintering temperature of the experimental material increased, the surface area significantly decreased while crystallite size increased. In vivo samples showed that the highly sintered BHA presented a significantly lower percentage of newly formed bone than the unheated one $(p=0.009)$. In addition, the percentage of bone-to-material contact (BMC) was significantly lowered in the highly sintered group when compared to the unsintered $(p=0.01)$ and $820^{\circ} \mathrm{C}$ sintered $(p=0.02)$ groups. Non-sintered or sintered at $820^{\circ} \mathrm{C}$ BHA seems to maintain a certain surface roughness allowing better bone regeneration and BMC. On the contrary, sintering of BHA at $1200^{\circ} \mathrm{C}$ has an effect on its morphological and structural characteristics and significantly modify its biological performance (osteoconductivity) and crystallinity.
\end{abstract}

Keywords: bone regeneraton; hydroxyapatite; osteoconduction; surface microtopograraphy; sintering

\section{Introduction}

Alveolar bone regeneration procedures are often performed to treat bone defects in order to replace missing teeth with dental implants in a multitude of situations in dentistry [1,2]. If autogenous bone grafts are still considered as the "gold standard" due to their osteogenic properties, their use is associated with several limitations, including limited bone supply, high resorption rates [3] and morbidity at the donor site, affecting patient compliance [4,5]. Therefore, biomaterials have become an alternative increasingly used in oral surgery, implantology and periodontology as bone void fillers allowing bone in-growth, acceleration of bone remodeling and osteoconductive structural guidance [6,7]. 
Calcium-phosphate-based $(\mathrm{CaP})$ materials have received a lot of attention due to their chemical similarity to bone, but also due to their excellent biocompatibility $[8,9]$. Natural and synthetic CaP materials such as hydroxyapatite (HA) and tricalcium phosphate (TCP) are the most commonly used biomaterials for alveolar bone regeneration [10]. TCP materials are osteoconductive and support bone growth by delivering calcium and phosphate ions in situ [11,12]; however, their fast biodegradation rate may not be the most appropriate to maintain bone volume overtime, which is indicated in cases of implant site development [12-14]. By contrast, HA which is also highly osteoconductive and similar to the mineral composition of natural bone, has the advantage of being more stable in body fluids $[10,14,15]$. Natural HA from bovine origin (bovine hydroxyapatites, BHA) remains the most used material in oral surgery, compared to synthetic HA, exhibiting physicochemical properties close to natural bone such as surface structure, morphology and microporosities (1-50 $\mu \mathrm{m})[16,17]$. According to some authors, these characteristics may influence the osteoconductivity of the materials and, therefore, their clinical performance [18-21]. Additionally, their slowly resorbable feature is of great interest in the field of dentistry and maxillofacial surgery, as one of the goals of bone regenerative treatment is to maintain the volume over time [22].

For safety reasons, xenogenic materials of bovine origin need to be completely deproteinized through thermal or chemical strategies, to eliminate the risk of transmission of bacteria, virus or prion particles [21,23-25]. One easy and cheap process to deproteinize BHA is sintering at temperatures higher than $1000{ }^{\circ} \mathrm{C}$, ensuring the complete removal of the organic compounds and improving mechanical properties (density, grain size, compressive, flexural and torsional strength) [26,27]. Commercially available xenogenic HA are manufactured with sintering temperatures up to $1300^{\circ} \mathrm{C}$. Despite the effect of sintering temperature on the physical and chemical characteristics of HA being well documented [16,26,28-32], its quantification on bone to material contact is poorly investigated. Thus, it is essential for the clinician to know what is the biological impact of this particular manufacturing process. Sintering hydroxyapatite has a significant impact on the surface properties; involving surface roughness, on microstructure including the crystallinity and microporosity [33-35] and may, therefore, influence the in vivo biological performance of the biomaterial [20,36,37]. Structural characteristics, such as microporosity, surface roughness, and specific surface area were shown to be of great importance in promoting protein adsorption on the material surface and capillary effect, and would consequently influence cell adhesion, proliferation, and bone tissue growth [17,38-42]. The physical characteristics seem to be a key feature, significantly influencing bone-regeneration outcomes [39].

The primary objective of this study was to investigate the effect of different sintering temperatures of chemically-deproteinized bovine hydroxyapatite in vivo in terms of biological performance (new bone formation and osteoconductivity). The secondary objective was to correlate the in vivo results with the structural and morphological characterization of the studied biomaterials.

\section{Materials and Methods}

\subsection{Experimental Biomaterials}

Three experimental hydroxyapatite xenografts from bovine origin were tested in the present study for physicochemical characterization and biological evaluations. The three groups were chemically deproteinized, in which the complete elimination of organic residues was performed under sub-critical conditions and a continuous flow of a basic solution following the patented extraction method developed by Wishbone SA (WO 2015/049336 A1) [44]. After elimination of the organic compounds, the two BHA samples were sintered under atmospheric conditions for $30 \mathrm{~min}$ at $820{ }^{\circ} \mathrm{C}$ (HA820) or $1200{ }^{\circ} \mathrm{C}$ (HA1200) while the third one was not sintered (HAN). The temperature of $820^{\circ} \mathrm{C}$ was chosen based on mechanical tests and scanning electronic microscopy (SEM) analysis regarding the physicochemical characteristics. In both cases, the sintering was performed as follows: the material was introduced in the furnace once the temperature had reached $800^{\circ} \mathrm{C}$; then the furnace heated until it achieved the sintering temperature $\left(820\right.$ or $\left.1200^{\circ} \mathrm{C}\right)$; the material was sintered during $30 \mathrm{~min}$ 
at the chosen temperature; after $30 \mathrm{~min}$, the furnace was shut down and the material was retrieved once the furnace had naturally reached room temperature again. All sintering parameters (time and temperature) were controlled by the internal controller of the furnace. The samples, HAN, HA820 and HA1200, were further sterilized in a drying oven at $120^{\circ} \mathrm{C}$. The material was not rinsed between sintering and sterilization. For all samples, small granules (particles size: 250-1000 $\mu \mathrm{m}$ ) were used

\subsection{Animals}

Yucatan mini-pigs were used for this study because their bone turns over in a similar manner to that of humans. Moreover, these animals are used in dental research due to similarities with humans in tooth development eruption time and sequence of tooth eruption [45]. The animals were 18 months old with a weight between 50 to $60 \mathrm{~kg}$ and presenting a complete eruption of the permanent teeth. All experimental procedures and protocols used in this investigation were reviewed and approved by the CIRE platform agreement number A37-175-4, Tours, France. The Animal Research Reporting of In Vivo Experiments (ARRIVE) guidelines as well as national and European legislation were carefully followed.

\subsection{Study Design}

Before implantation, the raw experimental biomaterials were characterized by scanning electronic microscopy (SEM) for qualitative analysis, measurement of the surface specific area (BET) and by X-ray diffractometry (XRD) to identify the crystalline phases and measurement of the crystallite size. The biological performance of the biomaterials was then evaluated in vivo in a mini-pig model (Figure 1). Dental extractions (T0) were performed in the maxillae of 5 mini-pigs. After a healing period of 3 months, six standardized bone socket defects were created per animal (3 per hemi-maxilla) and then filled with each of the three experimental biomaterials. A total of 10 samples per condition were considered for analyses. The software GPower was used to calculate the total sample size for 3 groups of biomaterial considering a statistical power of 0.8 and an effect size of 0.6 obtaining a total sample size of 30. Given the number of 6 implantation sites per animal, a total of 5 mini-pigs were chosen for this study. Euthanasia was performed after a healing period of 3 months, and the samples were subjected to non-decalcified histological analysis and histomorphometry.

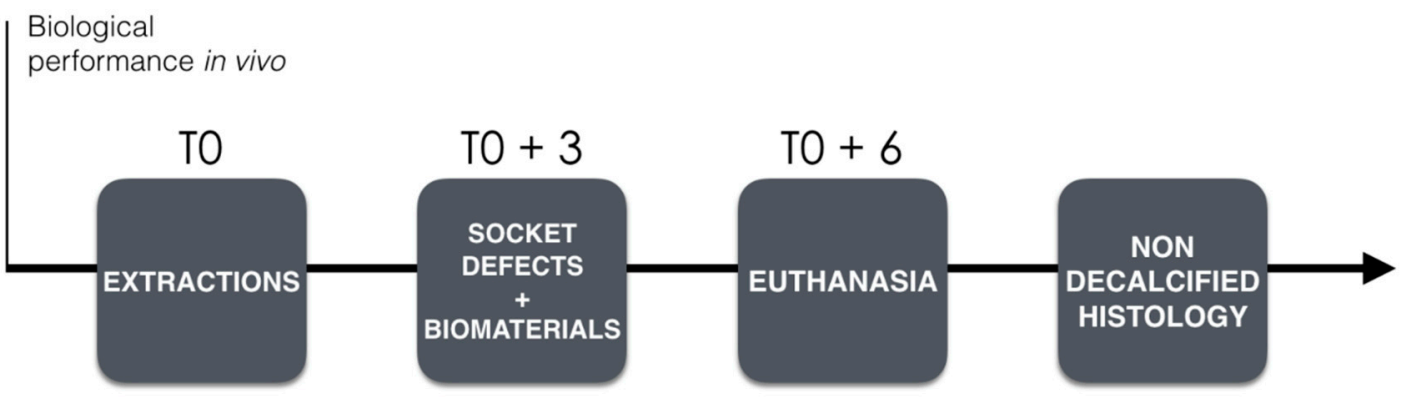

Figure 1. Study time line on biological performance.

\subsection{Scanning Electronic Microscopy (SEM) Analysis}

The three biomaterials were mounted on a glass slide double-sided carbone tape with platinum $(20 \mathrm{~nm})$ coated in a Balzers SCD030 sputtering unit. The surface characteristics were then captured using a scanning electron microscope ESEM-FEG XL30 (Philips Electron Optics, Hillsboro, OR, USA) at magnification levels of $\times 20,000, \times 5000$, and $\times 50$ for descriptive analysis.

\subsection{Brunauer-Emmett-Teller (BET) Specific Surface Area Analysis}

The specific surface area of each product was measured by $\mathrm{N}_{2}$ adsorption according to the Brunauer-Emmett-Teller (BET) method. Nitrogen adsorption-desorption isotherms were registered on a TriStar 3000 equipment (Micromeritics, Norcross, GA, USA). Prior to the measurements, the samples 
were degassed overnight under vacuum at $120^{\circ} \mathrm{C}$ on a VacPrep 061 (Micromeritics, Norcross, GA, USA). For each product, the measurement was repeated two times on three independent samples.

\subsection{X-ray Diffraction (XRD) Analysis}

Powder X-ray diffraction (XRD) was performed in Bragg-Brentano geometry using a Bruker D8 Twin-Twin diffractometer with $\mathrm{Cu} \mathrm{K} \alpha$ radiation (Billerica, MA, USA). The three products were ground into fine powders using an agate mortar. Three independent diffractograms were collected on each product in the $3^{\circ}-70^{\circ} 2 \theta$-range with a $0.02^{\circ}$ step size. The TOPAS software [46] was used to estimate the crystallite size; structure parameters for the hydroxyapatite phase were taken from the PDF 01-085-5086 reference (ICCD PDF4+ database) and the fundamental parameters approach was used to model the instrumental contribution to the reflection profiles. The crystallite size contribution to the peak profiles was modeled as lorentzian and convoluted with the instrumental contribution; the crystallite size (CS) and the integral breadth $\beta$ of the lorentzian (= area under the diffraction peak divided by maximum height of the peak) are related through the equation $C S=\lambda /(\beta \cos \theta)$ where $\lambda$ is the $\mathrm{Cu} \mathrm{K}$ alpha1 wavelength and $\theta$ is half of the $2 \theta$ angle [47].

\subsection{Surgical Procedure}

All the animals were sedated with xylazine (Ronpums, $1 \mathrm{mg} / \mathrm{kg}$, Bayer, Munchen, Germany) and imalgene 1000 (Imalgene ${ }^{\circledR}, 15 \mathrm{mg} / \mathrm{kg}$, Merial Laboratory, Lyon, France). During the surgery, the animals inhaled $\mathrm{O}_{2}$, were surveyed with an electrocardiogram and were maintained with a perfusion of imalgene 1000 (Imalgene ${ }^{\circledR}, 15 \mathrm{mg} / \mathrm{kg}$, Merial Laboratory, Lyon, France) in the saline. One hour before surgery, an injection of rimadyl ${ }^{\circledR}$ (carprofen, Kalamazoo, Michigan, USA) $1.5 \mathrm{mg} / \mathrm{kg}$ was performed. All the surgical procedures were performed under aseptic conditions. After disinfection of the surgical field with povidone iodine $10 \%$ (Iso-Betadine ${ }^{\circledR}$ titratable iodine, Meda Manufacturing, Merignac, France), a local anesthesia was performed at the maxillae ( $4 \%$ articaine hydrochloride with epinephrine 1:100,000 Septanest Sp; Septodont Inc. Créteil, Saint-Maur-des-Fossés, France). An intrasulcular incision and a full thickness flap were made from the canine to the second molar in each hemi arcade. The extractions of the four pre-molars and first molar were made carefully by a technique of root separation. After the extractions, the surgical sites were closed with resorbable sutures (Vicryl 4-0, Ethicon $\mathrm{GmbH}$, Norderstedt, Germany). The following post-surgical treatments and medication were administrated: antibiotic coverage of Amoxiciline for 5 days (Streptocillin ${ }^{\circledR}$ Vet, Boehringer Ingelheim, Copenhague, Danemark), analgesics (buprenorphine, Temgesic Schering-Plough, Brussels, Belgium) and daily mouth spray of chlorhexidine gluconate $0.2 \%$, (Corsodyl ${ }^{\circledR}$, GSK, Brentford, UK). After a healing period of 3 months, socket bone defects were created as follows. A supra crestal incision was performed and mucoperiosteal flaps were elevated to expose the right and left edentulous crest in the maxilla (Figure 2A). Three socket defects of $7 \mathrm{~mm}$ in depth and $5 \mathrm{~mm}$ in diameter were created in each hemi arcade (Figure 2B). The 3 biomaterials were randomly allocated in the standardized socket created at each hemi arcade and a collagen membrane (creos xenoprotect, Nobel Biocare AB, Göteborg, Sweden) was sized to cover the 3 bone defects in order to prevent the internal growing of soft tissue (Figure 2C,D). The mucoperiosteal flaps were sutured with non-resorbable sutures (polypropylene 4-0 FS-2; Ethicon, Edinburgh, UK).

\subsection{Euthanasia}

After a healing period of 6 months (T0+6), euthanasia was performed with an overdose of sodium pentobarbital at $3 \%$. The maxillary blocs were resected with an oscillating saw autopsy and the specimens containing the biomaterial sites and surrounding hard and soft tissues were placed in a $4 \%$ formaldehyde solution for sample fixation. 


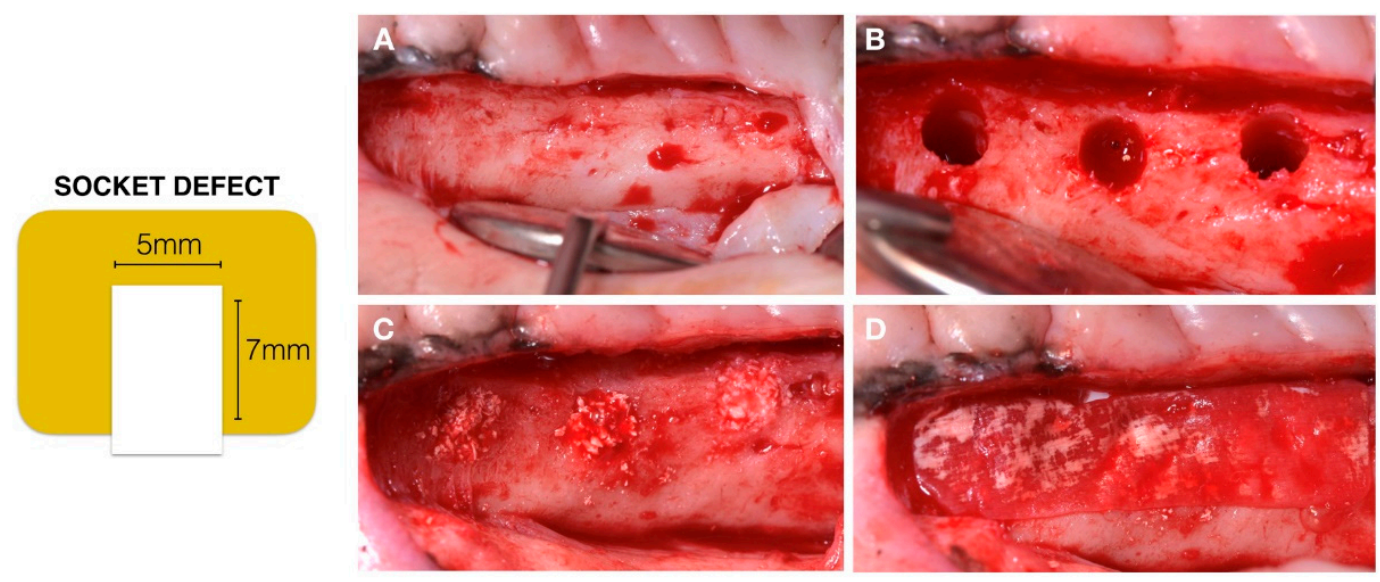

Figure 2. (A) Maxillae alveolar ridge after 3 months' extraction; (B) Socket defect; (C) Sockets filled with the 3 experimental biomaterials; (D) Collagen membrane covering socket defects.

\section{Histology}

Histological evaluation was performed on undecalcified polymethylmethacrylate (PMMA) sections. Dehydration was performed using an ascending concentration ethanol bath for $24 \mathrm{~h}$ : $1 \times 70^{\circ}, 1 \times 80^{\circ}, 2 \times 95^{\circ}$ and $3 \times 100^{\circ}$, and then by soaking for $24 \mathrm{~h}$ in acetone. Subsequently, samples were impregnated with methyl methacrylate for $48 \mathrm{~h}$ at $20^{\circ} \mathrm{C}$ with a refreshment of the medium. Finally, they were embedded in PMMA at $4{ }^{\circ} \mathrm{C}$ for 4 days. The sections were stained using methylene blue $(1 \%)$ for $90 \mathrm{~s}$ and basic fuchsin $(0.3 \%)$ for $25 \mathrm{~s}$ for a descriptive analysis. Sections were prepared using the cutting-grinding technique of hard tissues according to Donath and Breuner, 1982 [48].

\subsection{Histomorphometry}

The resulting sections (Figure 3) were digitalized using a Microscope (Leica 205A stereomicroscope Wetzlar Germany) in order to perform quantitative measurements of mineralized bone and biomaterial using image analysis software (ImageJ, National Institute of Health, Bethesda, MD, USA). The following parameters were calculated:

- Defect area: defined as the total area of the defect (Region Of Interest, ROI1) Figure 4A

- Regenerated area: defined as the defected area colonized by newly formed bone (ROI2) Figure 4B

- $\%$ of regeneration: proportion of ROI2/ROI1.

- $\%$ of newly formed bone, $\%$ of biomaterial, $\%$ of soft tissue within the overall defect area (ROI1)

- The osteoconductivity characterized by the bone to material contact (BMC) defined by the percentage of particles perimeter in contact with newly formed bone within the regenerated area (ROI2).

All images were segmented in 3 colors, red, green and purple, identifying respectively bone, biomaterial and soft tissue. The segmented images (Figure 5B) were then transformed into binary images allowing the individualization of each of the segmentations (Figure 5C). The software calculated the $\%$ of pixels present in each image. For the BMC, the 2 binary images (bone and biomaterial) were fused using a macrocode, drawing automatically the contact between the 2 segments. The total length of the contact lines was then measured and divided by the total perimeter of the particles contained in the ROI2. 
HAN
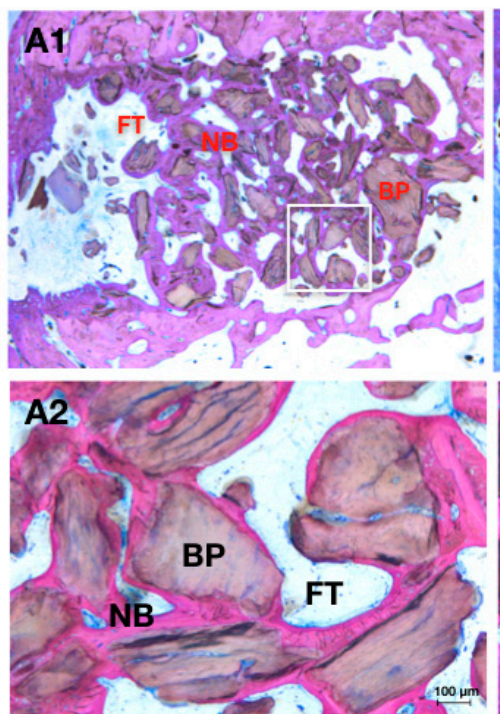

HA820
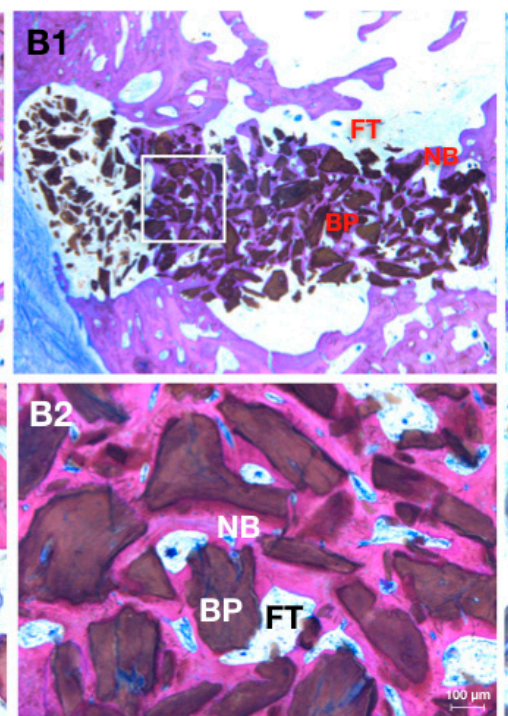

HA1200

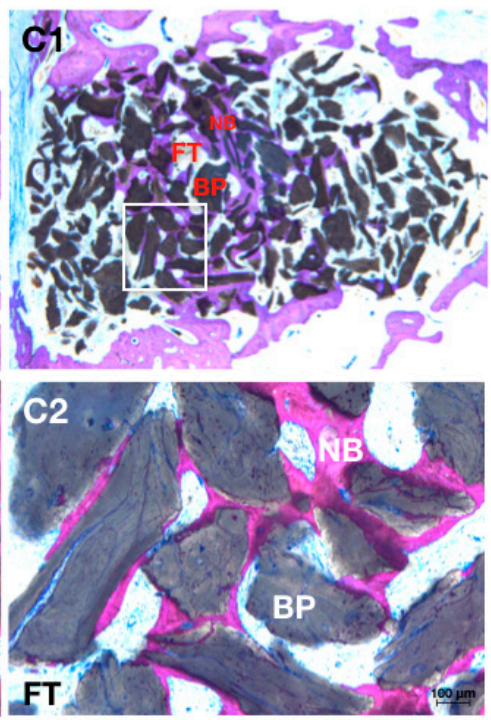

Figure 3. Descriptive histology after 3 months. BP, bone particle; NB, newly formed bone; FT, fibrous connective tissue.
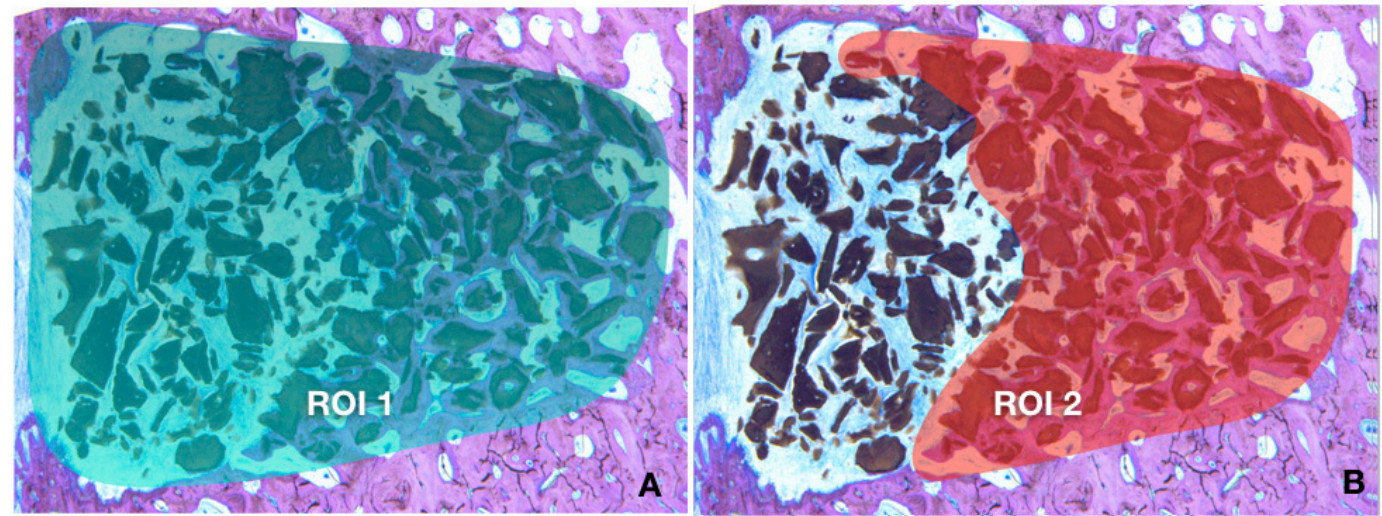

Figure 4. (A) Defect area (ROI1); (B) Regenerated area (ROI2).

\subsection{Statistical Analysis}

Results were presented as means and standard deviation (SD). A general linear mixed model (GLMM) was used for the comparisons of the parameters between the 3 groups (HAN, HA820 and HA1200) six measurements were done in the same pig. The Scheffé test was used to compare temperatures two by two. The results are considered to be significant at the $5 \%$ level $(p<0.05)$. Statistical analyses were performed using SAS software version 9.4 (SAS Institute, Cary, NC, USA). 

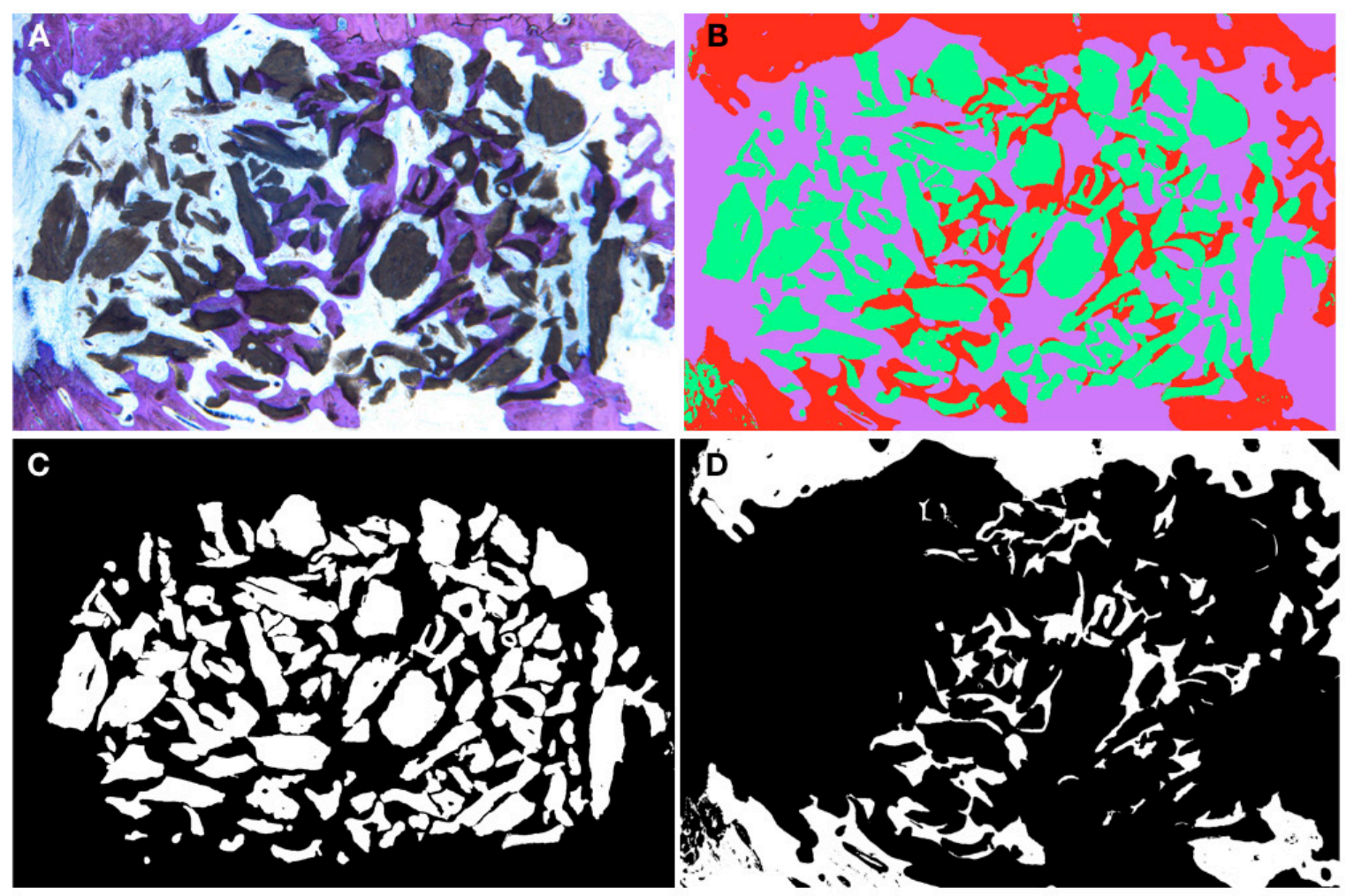

Figure 5. Histomorphometry segmentation steps; (A) Example of histological cut HA820; (B) Color segmentation using ImageJ; (C) Binary image isolating all the particles of bovine hydroxyapatites (BHA); (D) Binary image isolating the bone content.

\section{Results}

\subsection{Study Design}

During the healing period, one of the mini-pigs showed signs of paralysis of the hind legs and early euthanasia was performed. Therefore, a total of 24 bone defects and 8 samples per condition were available from the 4 remaining mini-pigs. All samples were assessed quantitatively and descriptively.

\subsection{SEM Characterization}

The SEM analysis provided a graphic insight of the HA structure with respect to porosity. SEM images of HAN, HA820 and HA1200 are displayed in Figure 6. The bone-like macro-architecture with macropores $(>50 \mu \mathrm{m})$ was visible in all samples. When looking at higher magnification, micropores could be observed in HAN and HA820 samples. HAN seems to preserve its surface roughness architecture while H820 changed into grain-like architecture presenting a rougher surface than HA1200 that presents a rather smooth surface and very few micro porosities.

\subsection{Surface Area, Pore Size and Pore Volume Analysis}

Surface area, pore size and volume are presented in Table 1. BET surface area analysis was carried out on all samples. From the average of two independent BET isotherms, the surface areas of HAN, HA820 and HA1200 were $\sim 36, \sim 4.2$ and $\sim 0.27 \mathrm{~m}^{2} / \mathrm{g}$ respectively, which showed that surface area substantially decreased with sintering. Barrett-Joyner-Halenda (BJH) pore size and volume analysis was also carried out. Both pore size and volume decreased with sintering temperature, with HAN, HA820 and HA1200 showing respective average pore sizes of $\sim 10, \sim 5.2$ and $\sim 4.5 \mathrm{~nm}$, and respective total pore volumes of $\sim 0.13, \sim 0.007$ and $\sim 0.003 \mathrm{~cm}^{3} / \mathrm{g}$. 


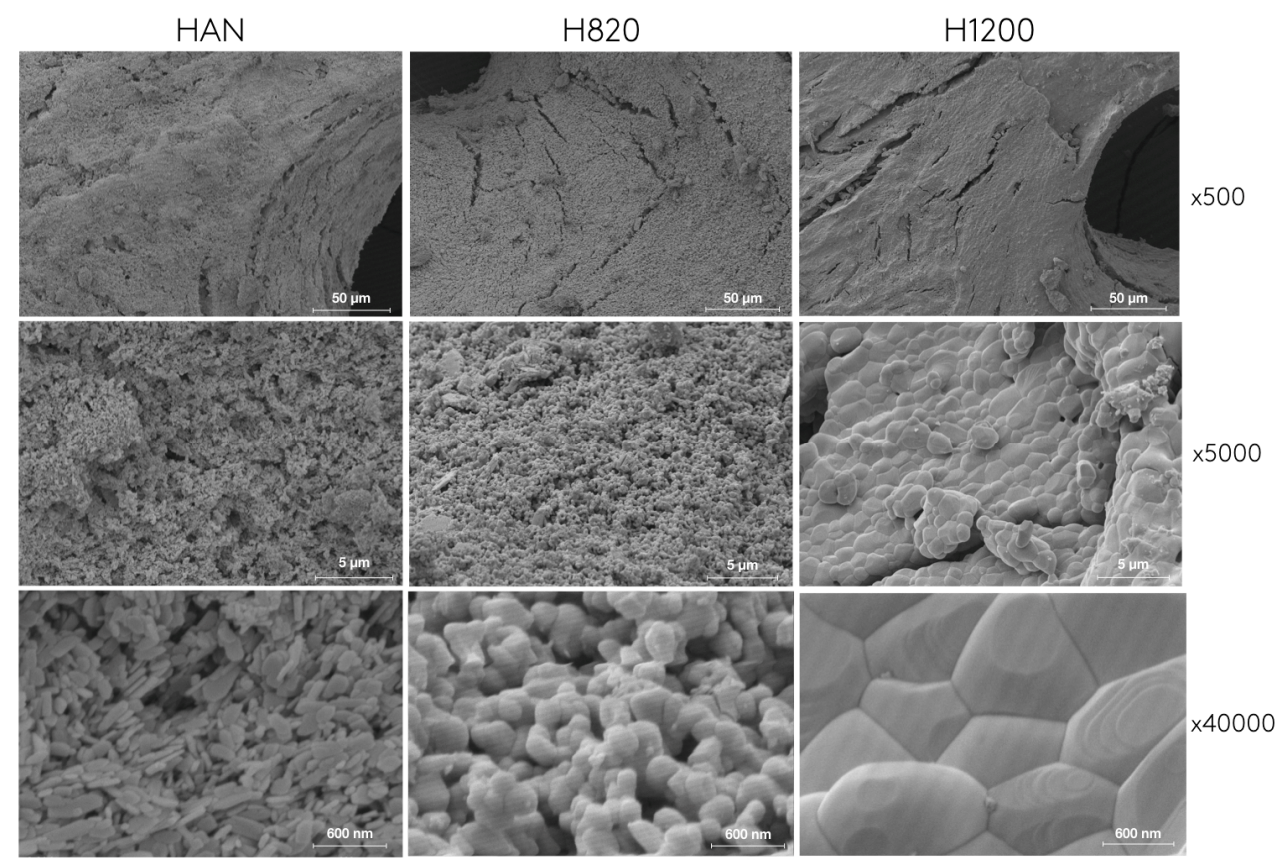

Figure 6. Scanning electronic micrographs (SEM) of the studied biomaterials at different magnifications: HAN: non-sintered HA; HA820: $820^{\circ} \mathrm{C}$ sintered HA; HA1200: $1200{ }^{\circ} \mathrm{C}$ sintered HA.

Table 1. Surface area, pore size and pore volume results.

\begin{tabular}{cccc}
\hline & HAN & HA820 & HA1200 \\
\hline Surface area $\left(\mathrm{m}^{2} / \mathrm{g}\right)$ & $\sim 36$ & $\sim 4.27$ & $\sim 0.27$ \\
Pore size $(\mathrm{nm})$ & $\sim 10$ & $\sim 5.2$ & $\sim 4.5$ \\
Total pore volume $\left(\mathrm{cm}^{3} / \mathrm{g}\right)$ & $\sim 0.13$ & $\sim 0.007$ & $\sim 0.003$ \\
\hline
\end{tabular}

\subsection{XRD Analysis}

The powder XRD patterns of representative samples are presented in Figure 7. For HAN, all observed peaks could be indexed to the formation of hydroxyapatite, $\mathrm{Ca}_{10}(\mathrm{PO} 4)_{6}(\mathrm{OH})_{2}\left(\mathrm{P}_{3} \mathrm{~m}\right.$; $a=9.424 \AA, b=9.424 \AA, \mathrm{c}=6.879 \AA, \alpha=90^{\circ}, \beta=90^{\circ}, \gamma=120^{\circ}$ ) [49]. For HA820 and HA1200, the majority of peaks could also be indexed to the formation of hydroxyapatite; however two other crystalline phases were detected. In HA820, a small broad peak at $\sim 43^{\circ} 2 \Theta$ was observed, which may correspond to the formation of $\mathrm{NaCaPO}_{4}\left(P n{ }_{1} a ; a=20.397 \AA, b=5.412 \AA, c=9.161 \AA, \alpha=90^{\circ}, \beta=90^{\circ}, \gamma=90^{\circ}\right)$ [50]. In HA1200, several additional peaks corresponding to the presence of $\mathrm{NaCaPO}_{4}$ were observed, and one additional peak at $\sim 37.5^{\circ} 2 \Theta$ that may correspond to the formation of $\mathrm{CaO}(F m \overline{3} m ; a=4.8152 \AA$, $b=4.8152 \AA, c=4.8152 \AA, \alpha=90^{\circ}, \beta=90^{\circ}, \gamma=90^{\circ}$ ) [51]. With an increase in sintering temperature, peaks in the majority hydroxyapatite phase became sharper and narrower, which was a result of an increase in the average crystallite size. When fitting the reflection with a model taking into account crystallite size and instrumental contributions, the average crystallite size increases from $29 \mathrm{~nm}$ in HAN, to $\sim 120 \mathrm{~nm}$ in HA820 to $\sim 230 \mathrm{~nm}$ in HA1200.

\subsection{Descriptive Histology}

After 3 months, newly formed bone was observed in the defect of all samples, mainly in the apical $2 / 3$ and adjacent to the lateral bone walls of the artificially created sockets (Figure 3). The typical structure of a newly formed bone is observed, with the presence of osteocytes entrapped by lamellar bone. Some chains of osteoblasts are also observed close to the newly formed bone as well as some blood vessels, with no visible differences between samples. No signs of inflammation were visible in any of the sections. Generally, samples of HA1200 showed less newly formed bone with more 
predominance of soft tissue between particles. In all groups it was possible to observe the particles in close contact with newly formed bone; however, this was predominantly observed in HAN and HA820.

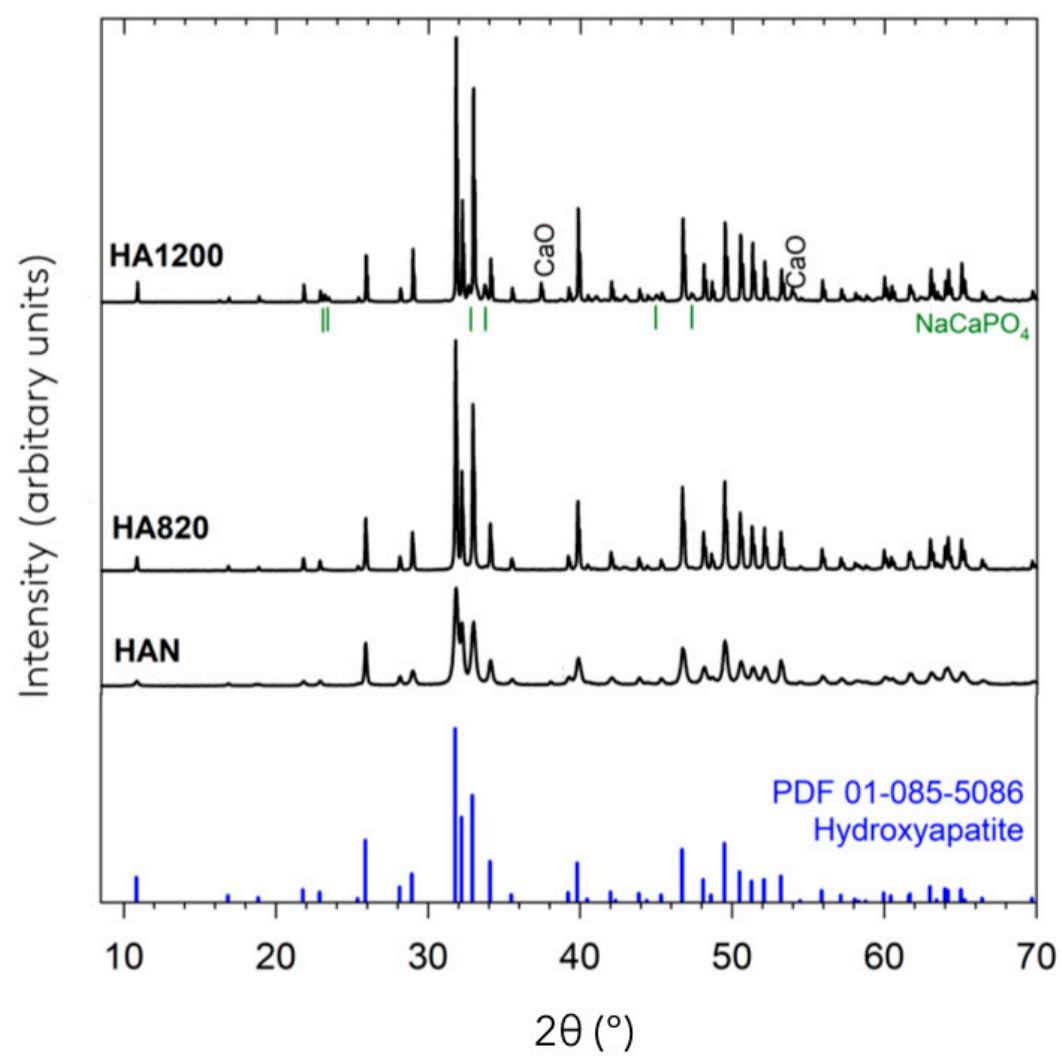

Figure 7. Comparison of the X-ray diffraction patterns of HAN, HA820, HA1200 with the reference spectra of hydroxyapatite.

\subsection{Quantitative Histomorphometric Analysis}

The $\%$ of regeneration (Figure $8 \mathrm{~A}$ ) was homogeneous in all groups with no significant differences $(p=0.10)$. In terms of $\%$ newly bone formation in the regenerated area (Figure $8 \mathrm{~B})$, there were significant differences between HAN and HA1200 $(p=0.009)$, although no significant differences were detected between HA820 and HAN $(p=0.119)$ and between HA820 and HA1200 $(p=0.115)$. The osteoconductivity (bone to material contact) (Figure 8 C) was also significantly higher in the groups HAN and HA820 compared to HA1200 (HAN vs. HA1200 $p=0.0192 ;$ HA820 vs. HA1200 $p=0.0234$ ). There was no significant difference between HAN and HA820 ( $p=0.8876)$.

A

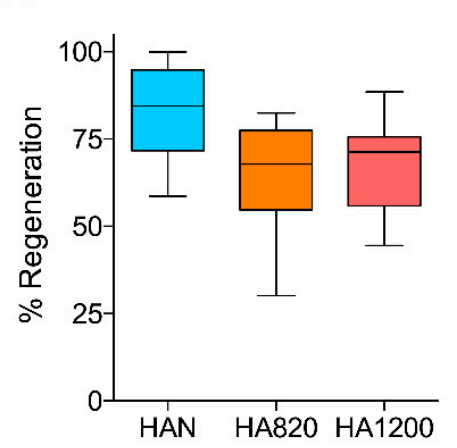

B

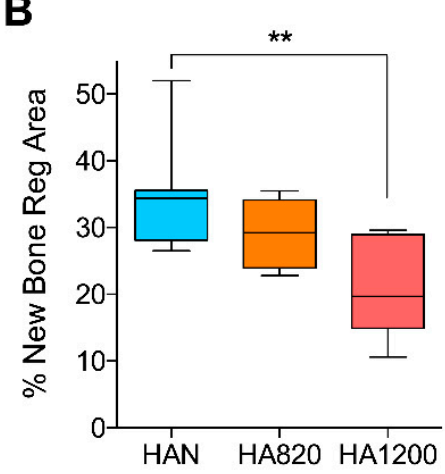

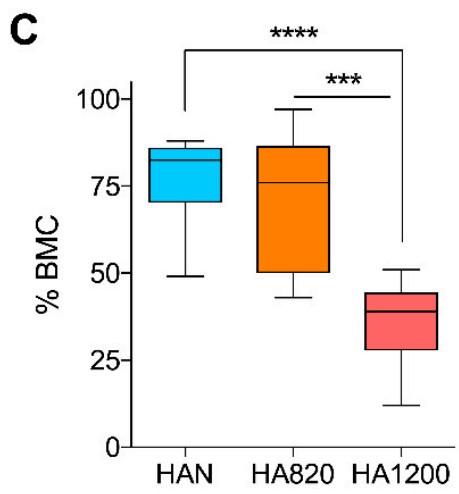

Figure 8. (A) \% of Regeneration; (B) \% of newly formed bone within the ROI2; (C) \% of Bone to material contact; $^{* *}=\mathrm{p}<0.01 ;{ }^{* * *}=\mathrm{p}<0.001 ;{ }^{* * * *}=\mathrm{p}<0.0001$. 


\subsection{Correlation Between Structural Characterization and Biological Performance}

For all samples, a positive correlation was observed between higher surface area values and \% of newly bone $(p=0.001)$ and $\%$ of BMC $(p=0.04)$. By contrast, a negative correlation was observed between higher crystallite size values and percentage of newly formed bone $(p=0.0002)$ and percentage of BMC $(p=0.001)$.

\section{Discussion}

The present study emphasized that the sintering process at high temperature modulates not only the structure but also the biological performance of chemically-deproteinized BHA.

The sintering process can result in increased crystallinity, appearance of new crystalline phases, decreased porosity and changes in the surface morphology. These characteristics may influence the performance results $[26,42]$ Nevertheless, the sintering temperature remains an important parameter for the improvement of mechanical properties of BHA [26,27,52].

The analysis of the hydroxyapatite structure by XRD revealed that the main crystalline phase present in all samples is hydroxyapatite. This proves that the chemical deproteinization process used here does not deteriorate the main crystalline phase initially present in bovine bones. The peaks corresponding to hydroxyapatite appear sharper when the sintering temperature increases, which can be interpreted as an increase in crystallite size and is considered a sign of high crystallinity. The crystallinity of a biomaterial is important as it influences its dissolution; therefore, high crystallinity materials display lower biodegradation rates and better volume stability overtime [53-56].

Additional traces of $\mathrm{NaCaPO}_{4}$ and $\mathrm{CaO}$ were also detected in $\mathrm{HA1200}$. The formation of $\mathrm{CaO}$ at $1200{ }^{\circ} \mathrm{C}$ could result from the decomposition of the carbonate content initially present in natural bone as already observed in other studies [57].

SEM analysis revealed that, from a descriptive point of view, the unsintered particles preserved their surface roughness architecture while the particles sintered at $820^{\circ} \mathrm{C}$ displayed a grain-like architecture. By contrast, the particles subjected to $1200^{\circ} \mathrm{C}$ suffered from structural changes on the surface morphology, presenting a smoother surface and fewer micro porosities compared to the two other BHA which can be correlated to the fusion of crystals as described by Patel, 2001 [58]. Looking at the porosity using BET analysis, the surface area decreased sharply from 36 to $4.2 \mathrm{~m}^{2} / \mathrm{g}$ when the particles were sintered at $820{ }^{\circ} \mathrm{C}$, and even to $0.27 \mathrm{~m}^{2} / \mathrm{g}$ when sintered at $1200{ }^{\circ} \mathrm{C}$. The specific surface area has been often mentioned in the literature as a significant parameter for bone regeneration $[37,54,58-60]$. It is indeed believed that a high specific surface area promotes extracellular matrix protein and cell adsorption, and thus favors bone formation [38]. According to the present results, the in vivo behavior of biomaterials seems to correlate better to their surface morphology than to their specific surface area. When the sample is sintered at low temperature $\left(820^{\circ} \mathrm{C}\right)$ the biological performance was not altered compared to the non-sintered sample. However, a clear change of the biological behavior was observed when the material was sintered at higher temperature $\left(1200^{\circ} \mathrm{C}\right)$ and the surface became smoother. Smooth surfaces are less expected to conduct cell colonization [61]. Indeed, the histomorphometric results of this study showed that the percentage of newly formed bone and the osteoconductivity (bone-to-material contact, $\mathrm{BMC}$ ) was equivalent for low and non-sintered hydroxyapatites, despite their significant difference in specific surface area while the BMC was significantly lower for the HA sintered at $1200{ }^{\circ} \mathrm{C}$. Therefore, it seems that the surface morphology of BHA (rather than specific surface area) is a key factor that should be considered when assessing their biological performance. These results seem in accordance with the literature about dental implants as the positive correlation of the roughness of implants and osteoconduction has been well described in several systematic reviews [62,63]. Nevertheless, it should be emphasized that one of the limitations of the present study was the lack of quantitative measurement of the micro-roughness of the experimental materials due to the complexity of this technique on particulate materials such as BHA. Another limitation of this study is that no comparison was made to BHA that did not undergo chemical deproteinization before sintering, which is how the commercially available sintered BHA products are currently made. Such variations in the manufacturing process may affect the 
physicochemical properties and provide different in vivo performance. Also, the specific production process steps might influence the BHA structure and consequently the clinical results. Nevertheless, good osteoconductivity and clinical results of sintered bovine bone has been reported many times [31,32].

The present study is one of the few taking into account the BMC to assess the biological performance of regenerative biomaterials since it is intended that each particle should be able to osteointegrate and have a high contact interface with newly formed bone, forming a tight bone-material network, which plays an important role in the subsequent implant placement and survival rates $[42,64,65]$.

Further studies should correlate the biological performance of biomaterials with different viscoelastic properties, hydrophilicity, physicochemical differences and surface roughness, in order to better explore the impact of these properties in promoting osteoconductivity and long-term volume stability in bone regenerative therapy. Such properties are influenced by the production process and origin of the biomaterial and should be considered as requirements in regenerative procedures $[6,42,57]$.

\section{Conclusions}

The sintering temperature affects the surface properties of chemically-deproteinized BHA biomaterials and these parameters influence the in vivo performance in terms of new bone formation and BMC. Non-sintered BHA or BHA sintered at low temperature $\left(820^{\circ} \mathrm{C}\right)$ seem to maintain a certain surface roughness of chemically-deproteinized BHA, allowing better bone regeneration and osteoconductivity (BMC). By contrast, sintering of BHA at $1200^{\circ} \mathrm{C}$ has an effect on its morphological and structural characteristics and significantly modifies its biological performance (osteoconductivity) and crystallinity. Despite the presented results being only obtained on chemically deproteinized BHA, they tend to reemphasize the importance of the production process on the in vivo performances of bone regeneration biomaterials. The osteointegration of each particle of BHA plays an important role on the quality of the regenerated bone. Clinicians should take into account that the process of biomaterial manufacturing can significantly influence the degree of bone regeneration, when choosing their biomaterial for regenerative treatments.

Author Contributions: B.D.C. was involved in the in vivo experiments, histomorphometry and biomaterial characterization. E.R., G.L. and F.L. performed the in vivo experiments and regenerative procedures; P.S. performed the non-decalcified histological analysis; E.D. and J.-F.A. were involved on the fabrication of the experimental biomaterial and characterization of it. All authors contributed to the analyses and discussion of the results as well as preparation of the manuscript.

Funding: This research received no external funding

Acknowledgments: The authors wish to express their gratitude to Laurence SEIDEL, Philippe COMPERE, Miguel QUESADA-GONZALEZ, Bénédicte VERTRUYEN and Andreas KAFIZAS for their input in the present manuscript.

Disclosures: The co-authors France Lambert, Eric Rompen and Geoffrey Lecloux are integrating members of the Wishbone SA board.

Conflicts of Interest: The authors declare no conflict of interest.

\section{References}

1. Esposito, M.; Mg, G.; Rees, J.; Karasoulos, D.; Felice, P.; Alissa, R.; Hv, W. Interventions for replacing missing teeth: Augmentation procedures of the maxillary sinus (Review) SUMMARY OF FINDINGS FOR THE MAIN COMPARISON. Cochrane Database Syst. Rev. 2010. [CrossRef]

2. Donos, N.; Mardas, N.; Chadha, V. Clinical outcomes of implants following lateral bone augmentation: Systematic assessment of available options (barrier membranes, bone grafts, split osteotomy). J. Clin. Periodontol. 2008, 35, 173-202. [CrossRef] [PubMed]

3. Dasmah, A.; Thor, A.; Ekestubbe, A.; Sennerby, L.; Rasmusson, L. Particulate vs. block bone grafts: Three-dimensional changes in graft volume after reconstruction of the atrophic maxilla, a 2-year radiographic follow-up. J. Cranio Maxillofac. Surg. 2012, 40, 654-659. [CrossRef] [PubMed]

4. Weibull, L.; Widmark, G.; Ivanoff, C.J.; Borg, E.; Rasmusson, L. Morbidity after chin bone harvesting-A retrospective long-term follow-up study. Clin. Implant Dent. Relat. Res. 2009, 11, 149-157. [CrossRef] 
5. Burchardt, H. The Biology of Bone Graft Repair. Clin. Orthop. Related Res. 1983, 174, 28-42. [CrossRef]

6. Trajkovski, B.; Jaunich, M.; Müller, W.D.; Beuer, F.; Zafiropoulos, G.G.; Houshmand, A. Hydrophilicity, viscoelastic, and physicochemical properties variations in dental bone grafting substitutes. Materials (Basel) 2018, 11, 215. [CrossRef]

7. Kolk, A.; Handschel, J.; Drescher, W.; Rothamel, D.; Kloss, F.; Blessmann, M.; Heiland, M.; Wolff, K.D.; Smeets, R. Current trends and future perspectives of bone substitute materials - From space holders to innovative biomaterials. J. Cranio Maxillofac. Surg. 2012, 40, 706-718. [CrossRef]

8. Hench, L.L. Bioceramics: From Concept to Clinic. J. Am. Ceram. Soc. 1991, 74, 1487-1510. [CrossRef]

9. Epple, M.; Ganesan, K.; Heumann, R.; Klesing, J.; Kovtun, A.; Neumann, S.; Sokolova, V. Application of calcium phosphatenanoparticles in biomedicine. J. Mater. Chem. 2010, 20, 18-23. [CrossRef]

10. Al-Sanabani, J.S.; Madfa, A.A.; Al-Sanabani, F.A. Application of calcium phosphate materials in dentistry. Int. J. Biomater. 2013, 2013. [CrossRef]

11. Metsger, D.S.; Dephilip, R.; Hayes, T.G. An Autoradiographic Study of Calcium Phosphate Ceramic Bone Implants in Turkeys. Clin. Orthop. Relat. Res. 1993, 283-294. [CrossRef]

12. Koepp, H.E.; Schorlemmer, S.; Kessler, S.; Brenner, R.E.; Claes, L.; Günther, K.-P.; Ignatius, A.A. Biocompatibility and osseointegration of $\beta$-TCP: Histomorphological and biomechanical studies in a weight-bearing sheep model. J. Biomed. Mater. Res. Part B Appl. Biomater. 2004, 70B, 209-217. [CrossRef] [PubMed]

13. Kwon, S.-H.; Jun, Y.-K.; Hong, S.-H.; Lee, I.-S.; Kim, H.-E.; Won, Y.Y. Calcium Phosphate Bioceramics with Various Porosities and Dissolution Rates. J. Am. Ceram. Soc. 2004, 85, 3129-3131. [CrossRef]

14. Chiba, S.; Anada, T.; Suzuki, K.; Saito, K.; Shiwaku, Y.; Miyatake, N.; Baba, K.; Imaizumi, H.; Hosaka, M.; Itoi, E.; et al. Effect of resorption rate and osteoconductivity of biodegradable calcium phosphate materials on the acquisition of natural bone strength in the repaired bone. J. Biomed. Mater. Res. Part A 2016, 104, 2833-2842. [CrossRef]

15. Ribeiro, N.; Sousa, S.R.; Monteiro, F.J. Influence of crystallite size of nanophased hydroxyapatite on fibronectin and osteonectin adsorption and on MC3T3-E1 osteoblast adhesion and morphology. J. Colloid Interface Sci. 2010, 351, 398-406. [CrossRef]

16. Gunduz, O.; Erkan, E.M.; Daglilar, S.; Salman, S.; Agathopoulos, S.; Oktar, F.N. Composites of bovine hydroxyapatite (BHA) and ZnO. J. Mater. Sci. 2008, 43, 2536-2540. [CrossRef]

17. Figueiredo, M.; Henriques, J.; Martins, G.; Guerra, F.; Judas, F.; Figueiredo, H. Physicochemical characterization of biomaterials commonly used in dentistry as bone substitutes-Comparison with human bone. J. Biomed. Mater. Res. Part B Appl. Biomater. 2010, 92, 409-419. [CrossRef]

18. Wu, J.; Li, B.; Lin, X. Histological outcomes of sinus augmentation for dental implants with calcium phosphate or deproteinized bovine bone: A systematic review and meta-analysis. Int. J. Oral Maxillofac. Surg. 2016, 45, 1471-1477. [CrossRef]

19. Jensen, S.S.; Broggini, N.; Hjørting-Hansen, E.; Schenk, R.; Buser, D. Bone healing and graft resorption of autograft, anorganic bovine bone and $\beta$-tricalcium phosphate. A histologic and histomorphometric study in the mandibles of minipigs. Clin. Oral Implants Res. 2006, 17, 237-243. [CrossRef]

20. Accorsi-Mendonça, T.; Conz, M.B.; Barros, T.C.; de Sena, L.Á.; Soares, G.d.; Granjeiro, J.M. Physicochemical characterization of two deproteinized bovine xenografts. Braz. Oral Res. 2008, 22, 5-10. [CrossRef]

21. Lei, P.; Sun, R.; Wang, L.; Zhou, J.; Wan, L.; Zhou, T.; Hu, Y. A new method for xenogeneic bone graft deproteinization: Comparative study of radius defects in a rabbit model. PLoS ONE 2015, 10, 1-17. [CrossRef] [PubMed]

22. Lambert, F.; Lecloux, G.; Rompen, E. One-Step Approach for Implant Placement and Subantral Bone Regeneration Using Bovine Hydroxyapatite: A 2-to 6-Year Follow-up Study. Int. J. Oral Maxillofac. Implants 2010, 25, 598-606. [PubMed]

23. Wenz, B.; Oesch, B.; Horst, M. Analysis of the risk of transmitting bovine spongiform encephalopathy through bone grafts derived from bovine bone. Biomaterials 2001, 22, 1599-1606. [CrossRef]

24. Baldini, N.; de Sanctis, M.; Ferrari, M. Deproteinized bovine bone in periodontal and implant surgery. Dent. Mater. 2011, 27, 61-70. [CrossRef]

25. Uklejewski, R.; Winiecki, M.; Musielak, G.; Tokłowicz, R. Effectiveness of various deproteinization processes of bovine cancellous bone evaluated via mechano-biostructural properties of produced osteoconductive biomaterials. Biotechnol. Bioprocess Eng. 2015, 20, 259-266. [CrossRef] 
26. Goller, G.; Oktar, F.N.; Agathopoulos, S.; Tulyaganov, D.U.; Ferreira, J.M.F.; Kayali, E.S.; Peker, I. Effect of sintering temperature on mechanical and microstructural properties of bovine hydroxyapatite (BHA). J. Sol-Gel Sci. Technol. 2006, 37, 111-115. [CrossRef]

27. Witek, L.; Smay, J.; Silva, N.R.F.A.; Guda, T.; Ong, J.L.; Coelho, P.G. Sintering effects on chemical and physical properties of bioactive ceramics. J. Adv. Ceram. 2013, 2, 274-284. [CrossRef]

28. Knowles, J.C.; Horton, J.A.; Bonfield, W. Rietveld Analysis on the Effect of Sintering Conditions on the Structure of Hydroxyapatite. Bioceramics 1994, 23-28. [CrossRef]

29. Barone, A.; Todisco, M.; Ludovichetti, M.; Gualini, F.; Aggstaller, H.; Torres-Lagares, D.; Rohrer, M.; Prasad, H.; Kenealy, J. A Prospective, Randomized, Controlled, Multicenter Evaluation of Extraction Socket Preservation Comparing Two Bovine Xenografts: Clinical and Histologic Outcomes. Int. J. Periodontics Restor. Dent. 2013, 33, 795-802. [CrossRef]

30. Spies, C.K.G.; Schnürer, S.; Gotterbarm, T.; Breusch, S.J. Efficacy of Bone Source ${ }^{\mathrm{TM}}$ and Cementek ${ }^{\mathrm{TM}}$ in comparison with Endobon ${ }^{\mathrm{TM}}$ in critical size metaphyseal defects, using a minipig model. J. Appl. Biomater. Biomech. 2010, 8, 175-185. [CrossRef]

31. Tawil, G.; Barbeck, M.; Unger, R.; Tawil, P.; Witte, F. Sinus Floor Elevation Using the Lateral Approach and Window Repositioning and a Xenogeneic Bone Substitute as a Grafting Material: A Histologic, Histomorphometric, and Radiographic Analysis. Int. J. Oral Maxillofac. Implants 2018, 33, 1089-1096. [CrossRef]

32. Takauti, C.A.Y.; Futema, F.; Junior, R.B.d.; Abrahao, A.C.; Costa, C.; Queiroz, C.S. Assessment of Bone Healing in Rabbit Calvaria grafted with three different Biomaterials. Braz. Dent. J. 2014, 25, 379-384. [CrossRef]

33. Joschek, S.; Nies, B.; Krotz, R.; Göpferich, A. Chemical and physicochemical characterization of porous hydroxyapatite ceramics made of natural bone. Biomaterials 2000, 21, 1645-1658. [CrossRef]

34. Figueiredo, M.; Fernando, A.; Martins, G.; Freitas, J.; Judas, F.; Figueiredo, H. Effect of the calcination temperature on the composition and microstructure of hydroxyapatite derived from human and animal bone. Ceram. Int. 2010, 36, 2383-2393. [CrossRef]

35. Etok, S.E.; Valsami-Jones, E.; Wess, T.J.; Hiller, J.C.; Maxwell, C.A.; Rogers, K.D.; Manning, D.A.C.; White, M.L.; Lopez-Capel, E.; Collins, M.J.; et al. Structural and chemical changes of thermally treated bone apatite. J. Mater. Sci. 2007, 42, 9807-9816. [CrossRef]

36. Li, X.; van Blitterswijk, C.A.; Feng, Q.; Cui, F.; Watari, F. The effect of calcium phosphate microstructure on bone-related cells in vitro. Biomaterials 2008, 29, 3306-3316. [CrossRef] [PubMed]

37. Habibovic, P.; Kruyt, M.C.; Juhl, M.V.; Clyens, S.; Martinetti, R.; Dolcini, L.; Theilgaard, N.; van Blitterswijk, C.A. Comparative in vivo study of six hydroxyapatite-based bone graft substitutes. J. Orthop. Res. 2008, 26, 1363-1370. [CrossRef] [PubMed]

38. Rouahi, M.; Champion, E.; Gallet, O.; Jada, A.; Anselme, K. Physico-chemical characteristics and protein adsorption potential of hydroxyapatite particles: Influence on in vitro biocompatibility of ceramics after sintering. Colloids Surfaces B Biointerfaces 2006, 47, 10-19. [CrossRef]

39. Espanol, M.; Mestres, G.; Luxbacher, T.; Dory, J.B.; Ginebra, M.P. Impact of Porosity and Electrolyte Composition on the Surface Charge of Hydroxyapatite Biomaterials. ACS Appl. Mater. Interfaces 2016, 8, 908-917. [CrossRef]

40. LeGeros, R.Z. Properties of osteoconductive biomaterials: Calcium phosphates. Clin. Orthop. Relat. Res. 2002, 395, 81-98. [CrossRef]

41. Klenke, F.M.; Liu, Y.; Yuan, H.; Hunziker, E.B.; Siebenrock, K.A.; Hofstetter, W. Impact of pore size on the vascularization and osseointegration of ceramic bone substitutes in vivo. J. Biomed. Mater. Res. Part A 2008, 85, 777-786. [CrossRef]

42. Lambert, F.; Bacevic, M.; Layrolle, P.; Schüpbach, P.; Drion, P.; Rompen, E.; Schupbach, P.; Drion, P.; Rompen, E. Impact of biomaterial microtopography on bone regeneration: Comparison of three hydroxyapatites. Clin. Oral Implants Res. 2017, 28, e201-e207. [CrossRef]

43. Kurkcu, M.; Benlidayi, M.E.; Cam, B.; Sertdemir, Y. Anorganic Bovine-Derived Hydroxyapatite vs $\beta$-Tricalcium Phosphate in Sinus Augmentation: A Comparative Histomorphometric Study. J. Oral Implantol. 2012, 38, 519-526. [CrossRef]

44. Rompen, E.; Lambert, F.; Lecloux, G.; Moniotte, P. Materiau De Regeneration Osseuse Et Son Procede De Fabrication. Pat. WO 2015/049336 A1, 2015.

45. Wang, S.; Liu, Y.; Fang, D.; Shi, S. The miniature pig: A useful large animal model for dental and orofacial research. Oral Dis. 2007, 13, 530-537. [CrossRef] 
46. Cheary, B.Y.R.W.; Coelho, A. A Fundamental Parameters Approach to X-ray Line-Profile Fitting. J. Appl. Crystallogr. 1992, 109-121. [CrossRef]

47. Krill, C.E.; Haberkorn, R.; Birringer, R. Specification of microstructure and characterization by scattering techniques, Handb. Nanostruct. Mater. Nanotechnol. 2000, 155-211. [CrossRef]

48. Donath, K.; Breuner, G. A method for the study of undecalcified bones and teeth with attached soft tissues*. J. Oral Pathol. Med. 1982, 11, 318-326. [CrossRef] [PubMed]

49. Sudarsanan, K.; Young, R.A. Significant precision in crystal structural details. Holly Springs hydroxyapatite. Acta Crystallogr. Sect. B 1969, 25, 1534-1543. [CrossRef]

50. Amara, M.B.; Vlasse, M.; le Flem, G.; Hagenmuller, P. Structure of the low-temperature variety of calcium sodium orthophosphate, NaCaPO4. Acta Crystallogr. Sect. C 1983, 39, 1483-1485. [CrossRef]

51. Shen, C.H.; Liu, R.S.; Lin, J.G.; Huang, C.Y. Phase stability study of $\mathrm{La}_{1.2} \mathrm{Ca}_{1.8} \mathrm{Mn}_{2} \mathrm{O}_{7}$. Mater. Res. Bull. 2001, 36, 1139-1148. [CrossRef]

52. Yetmez, M.; Erkmen, Z.E.; Kalkandelen, C.; Ficai, A.; Oktar, F.N. Sintering effects of mullite-doping on mechanical properties of bovine hydroxyapatite. Mater. Sci. Eng. C 2017, 77, 470-475. [CrossRef]

53. Kusrini, E.; Sontang, M. Characterization of x-ray diffraction and electron spin resonance: Effects of sintering time and temperature on bovine hydroxyapatite. Radiat. Phys. Chem. 2012, 81, 118-125. [CrossRef]

54. Bohner, M. Calcium orthophosphates in medicine: From ceramics to calcium phosphate cements. Injury 2000, 31. [CrossRef]

55. Riachi, F.; Naaman, N.; Tabarani, C.; Aboelsaad, N.; Aboushelib, M.N.; Berberi, A.; Salameh, Z. Influence of material properties on rate of resorption of two bone graft materials after sinus lift using radiographic assessment. Int. J. Dent. 2012, 2012. [CrossRef]

56. Fernández, M.P.R.; Gehrke, S.A.; Martinez, C.P.A.; Guirado, J.L.C.; de Aza, P.N. SEM-EDX study of the degradation process of two xenograft materials used in sinus lift procedures. Materials (Basel) 2017, 10, 542. [CrossRef] [PubMed]

57. Tadic, D.; Epple, M. A thorough physicochemical characterisation of 14 calcium phosphate-based bone substitution materials in comparison to natural bone. Biomaterials 2004, 25, 987-994. [CrossRef]

58. Patel, N.; Gibson, I.R.; Ke, S.; Best, S.M.; Bonfield, W.; Materials, B.; Mary, Q.; College, W.; Road, M.E. Calcining infuence on the powder properties of hydroxyapatite. J. Mater. Sci. Mater. Med. 2001, 2, 181-188. [CrossRef] [PubMed]

59. Tan, C.Y.; Ramesh, S.; Aw, K.L.; Yeo, W.H.; Hamdi, M.; Sopyan, I. Effect of powder calcination on the sintering of hydroxyapatite. Med. J. Malaysia 2008, 63 (Suppl A), 87-88. [CrossRef]

60. Wang, A.J.; Lu, Y.P.; Zhu, R.F.; Li, S.T.; Xiao, G.Y.; Zhao, G.F.; Xu, W.H. Effect of sintering on porosity, phase, and surface morphology of spray dried hydroxyapatite microspheres. J. Biomed. Mater. Res. Part A 2008, 87, 557-562. [CrossRef]

61. Deligianni, D.D.; Katsala, N.D.; Koutsoukos, P.G.; Missirlis, Y.F. Effect of surface roughness of hydroxyapatite on human bone marrow cell adhesion, proliferation, differentiation and detachment strength. Biomaterials 2000, 22, 87-96. [CrossRef]

62. Wennerberg, A.; Albrektsson, T. Effects of titanium surface topography on bone integration: A systematic review. Clin. Oral Implants Res. 2009, 20, 172-184. [CrossRef]

63. Shalabi, M.M.; Gortemaker, A.; van Hof, M.A. Critical reviews in oral biology \& medicine Implant Surface Roughness and Bone Healing. J. Dent. Res. 2006, 496-501. [CrossRef]

64. Molly, L.; Vandromme, H.; Quirynen, M.; Schepers, E.; Adams, J.L.; van Steenberghe, D. Bone Formation Following Implantation of Bone Biomaterials Into Extraction Sites. J. Periodontol. 2008, 79, 1108-1115. [CrossRef] [PubMed]

65. Lambert, F.; Leonard, A.; Lecloux, G.; Sourice, S.; Pilet, P.; Rompen, E. A Comparison of Three Calcium Phosphate-Based Space Fillers in Sinus Elevation: A Study in Rabbits. Int. J. Oral Maxillofac. Implants 2013, 28, 393-402. [CrossRef] [PubMed]

(C) 2019 by the authors. Licensee MDPI, Basel, Switzerland. This article is an open access article distributed under the terms and conditions of the Creative Commons Attribution (CC BY) license (http://creativecommons.org/licenses/by/4.0/). 